\title{
The Impact of Residual Stress Relaxation on Fatigue Life Enhancing Effect of Cold Expansion
}

\author{
GUAN Di ${ }^{1, a}$, SUN Qin ${ }^{1, b}$ \\ ${ }^{1}$ School of Aeronautic, Northwestern Polytechnical University, Xi'an, Shanxi, 710072, China \\ aguanfei@mail.nwpu.edu.cn, bsunqin@nwpu.edu.cn
}

Keywords: Residual Stress, Stress Relaxation, Cold Expansion, Fatigue Life Enhancing Ratio

\begin{abstract}
A numerical analysis was performed, using three-dimensional finite element method to assess the impact of residual stress relaxation on the fatigue strength benefit of cold expansion. Fatigue lives of cold expansion hole made from aluminium alloy 7050-T7451 under different relaxation time are presented, the results reveal that the fatigue life enhancing ratio is inversely proportional to the stress relaxation time, residual stress relaxation can weaken the benefit of cold expansion strongly.
\end{abstract}

\section{Introduction}

Mechanical joints are used extensively in aircraft structures. However, these connections are inherently vulnerable to fatigue because the stress concentration around fastener holes, statistics show that fatigue fracture of fastener holes account for $70 \%$ in aircraft structures failure [1]. To improve fatigue life of fastener holes, in the 1970s, one technique named as cold expansion was presented by Boeing Company and been widely used in the last decades. Fatigue life improvement is attributed to the presence of residual compressive stress induced by cold expansion as the residual stress can reduce stress concentration effectively at hole edge, the benefits of cold expansion have been well documented in previous studies [2 5].

Generally, the desired service life of many aircraft structures beyond twenty years, for these applications, residual stress relaxation in room temperature become a significant factor in limiting the beneficial effects of cold expansion. To determine residual stress variation, one method is to use a fracture mechanics approach [6], this method is practical but obtain only the average value of residual stress in observation area.

A more popular method of calculating residual stresses is numerically using finite element analysis [7 9]. This paper describes how finite element analysis has been carried out to establish the residual circumferential stress relaxation around a cold expanded hole made from aluminium alloy 7050-T7451; fatigue lives under different relaxation time are presented to study the impact of residual stress relaxation on fatigue life enhancing effect of cold expansion also.

\section{Material properties and finite element model}

Split sleeve cold expansion is adopted. Specimen was made from aluminium alloy 7050-T7451, the yield strength $\sigma_{y}=460 \mathrm{MPa}$, tensile strength $\sigma_{b}=530 \mathrm{MPa}$, and fatigue limit $\sigma_{f}=142 \mathrm{MPa}$ at room temperature, respectively, the Young's modulus and Poisson's ratio were measured to be $71 \mathrm{GPa}$ and 0.33 [10]. For the steel sleeve and mandrel a linear elastic material relationship was assumed with Young's modulus of $210 \mathrm{GPa}$ and Poisson's ratio of 0.3 .

A 3-D finite element model was used to simulate the process of split sleeve cold expansion, stress relaxation and fatigue. Only one eighth of specimen and half of mandrel were needed in the simulation due to their symmetry with respect to the $\mathrm{X}-\mathrm{Y}, \mathrm{X}-\mathrm{Z}$ and $\mathrm{Y}-\mathrm{Z}$ planes, 8-node linear brick reduced integration element (C3D8R) was used. In addition, two sets of contact elements were used between the sleeve and the plate, the sleeve and the mandrel. In FEA model, the plate is $80 \mathrm{~mm}$ long $\times 17.5 \mathrm{~mm}$ wide $\times 2 \mathrm{~mm}$ thick, the hole diameter is $4.51 \mathrm{~mm}$, the split sleeve outer diameter is 
$4.10 \mathrm{~mm}$ and inner diameter is $3.70 \mathrm{~mm}$, the mandrel diameter is $4.40 \mathrm{~mm}$ with $6.43 \%$ interference. All analysis was carried out by the finite element package ABAQUS 6.10.

The finite element model is presented in Fig.1.

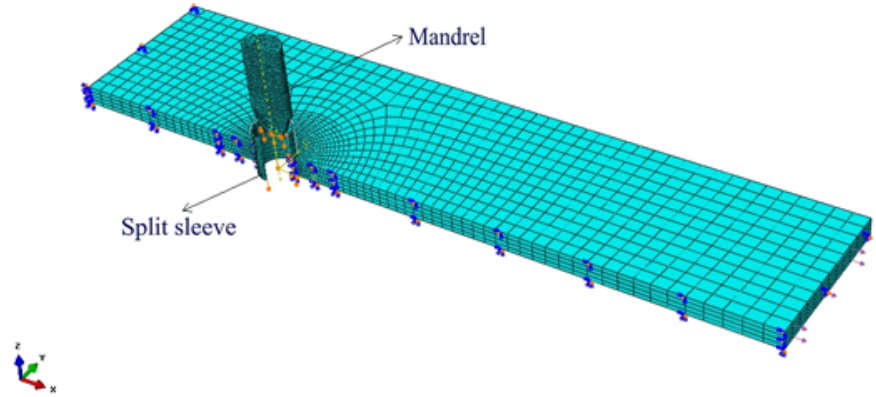

Fig.1 3-D finite element model

\section{Numerical simulation method}

The whole calculation steps are given in Fig.2.

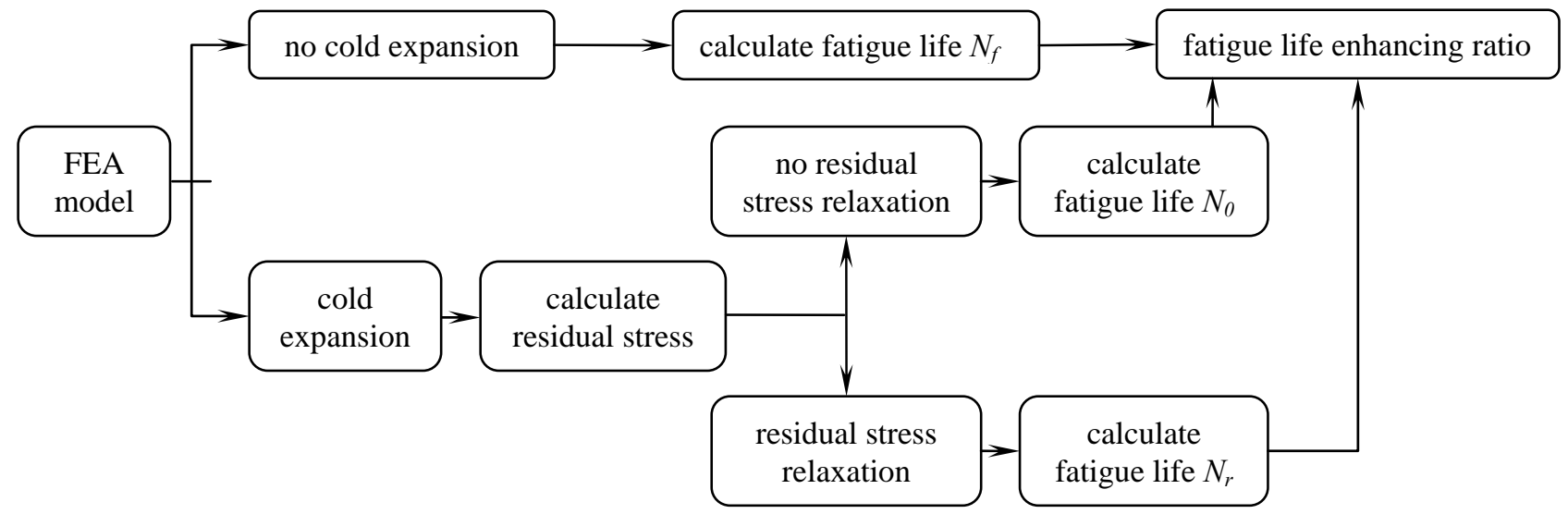

Fig.2 Illustration of calculation steps

The residual stress relaxation can be obtained by calculating creep strain [9]. For room temperature creep under low stress, the power-law model for creep strain is

$\dot{\widetilde{\varepsilon}}_{c r}=A \tilde{\sigma}^{n} t^{m}$

Where, $\dot{\widetilde{\varepsilon}}_{c r}$ is the uniaxial equivalent creep strain rate; $\tilde{\sigma}$ is the mises equivalent stress, $t$ is the total creep time, $A, n$, and $m$ are material constants depend on temperature, for aluminium alloy 7050-T7451

$$
A=2.7437 \times 10^{-19}, n=6, m=-0.1471
$$

In this paper, Select stress ampltitude $S_{a}=150 \mathrm{Mpa}$, stress ratio $R=-1,0.06$ for calculating fatigue life, a corrected damage law for high cycle fatigue is used for calculating fatigue life [11 12].

\section{Results and discussions}

Fig. 3 shows the animation process of cold expansion.
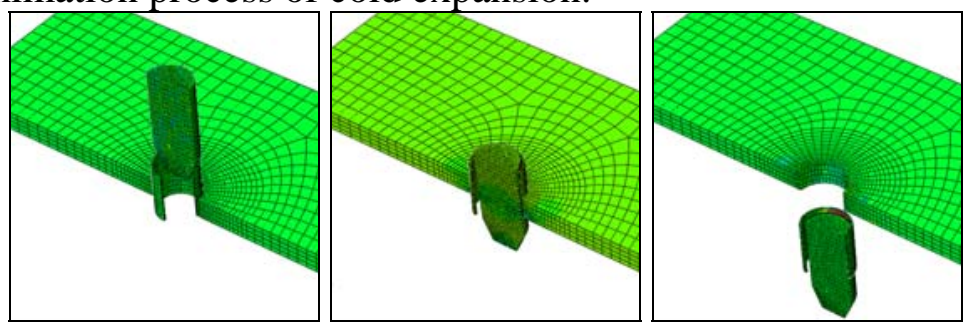

Fig.3 Process of cold expansion 
Fig. 4 shows how the residual circumferential stress(along $\mathrm{X}$-axis) distribution change with time around hole edge.

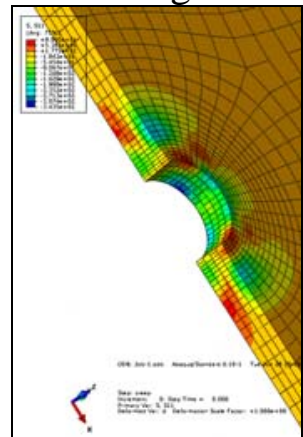

(a)0a

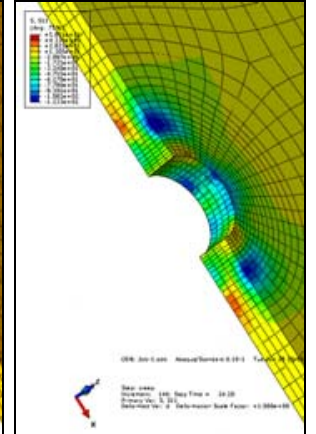

(b)1a

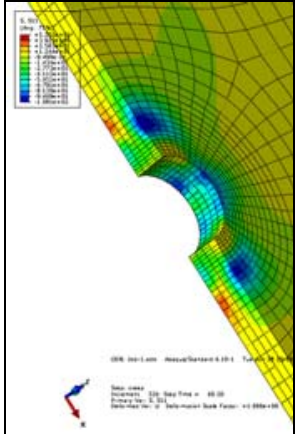

(c) 5 a

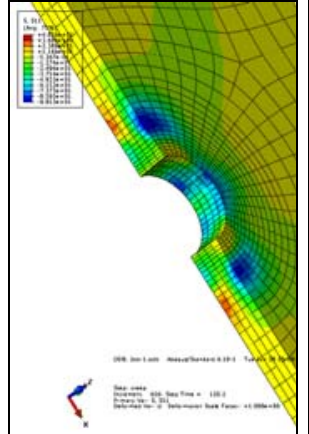

(d)10a

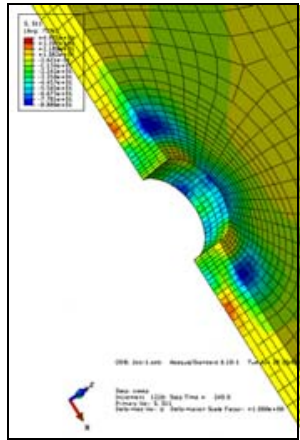

(e)20a

Fig.4 Residual circumferential stress distribution after different years

The residual circumferential stress along path-1 in different time is presented in Fig.5.

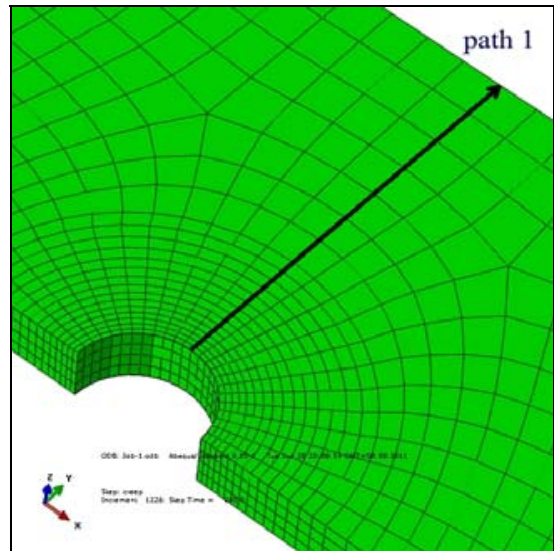

(a)

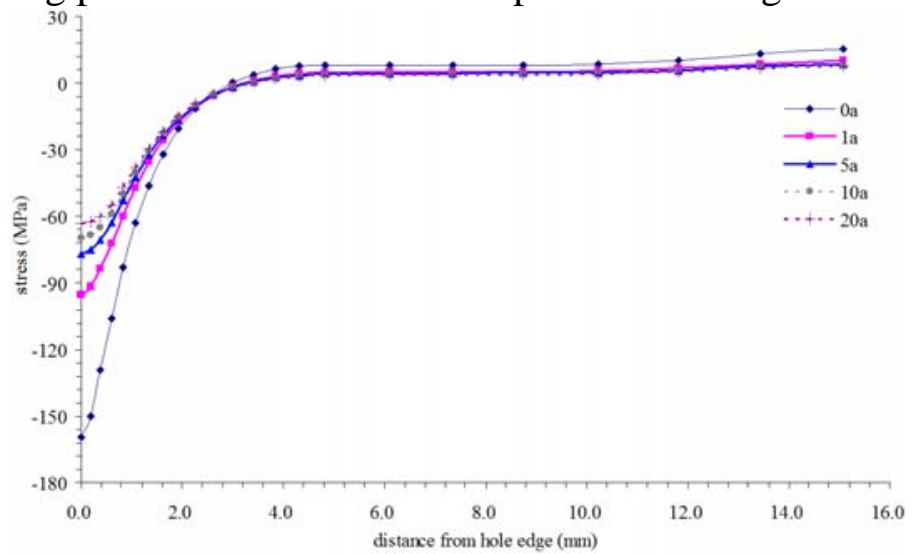

(b)

Fig.5 Residual circumferential stress distribution along path-1

The residual circumferential stress distribution in fatigue loading and failure elements are shown in Fig.6. The FE simulation shows that the maximum longitudinal stress occurring a distance away from the hole edge, the fact that fatigue cracks initiated and propagated from the hole edge suggest that the effect of residual stress is not enough to eliminate the stress concentration around hole edge.
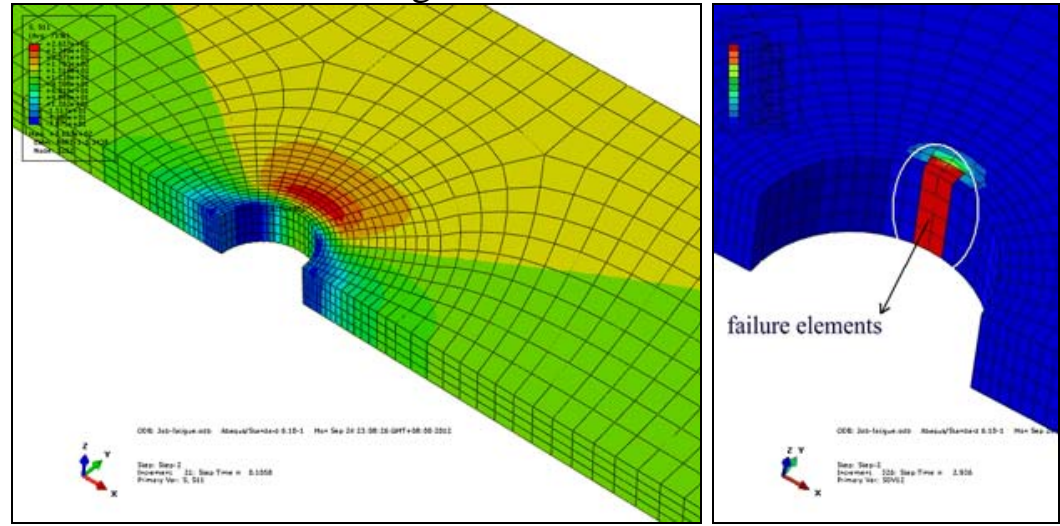

Fig.6 Illustration for fatigue life calculation

Tab.1 indicates the fatigue lives under different loading situations.

Tab.1 Comparison between fatigue lives under different loading situations

\begin{tabular}{|c|c|c|c|c|c|}
\hline $\begin{array}{c}\text { stress ampltitude } \\
\text { (MPa) }\end{array}$ & Stress ratio & Cold expansion & $\begin{array}{c}\text { Relaxation time } \\
\text { (year) }\end{array}$ & Fatigue life & life enhancing ratio \\
\hline \multirow{4}{*}{150} & & No & $/$ & 69500 & 1.00 \\
\cline { 2 - 5 } & \multirow{4}{*}{-1} & Yes & 0 & 585000 & 8.42 \\
\cline { 2 - 5 } & & Yes & 1 & 345000 & 4.96 \\
\cline { 2 - 5 } & & Yes & 5 & 267500 & 3.85 \\
\cline { 2 - 5 } & & Yes & 10 & 192500 & 2.77 \\
\cline { 2 - 5 } & & Yes & 20 & 142500 & 2.05 \\
\hline
\end{tabular}




\begin{tabular}{|c|c|c|c|c|c|}
\hline \multirow{4}{*}{} & No & $/$ & 82500 & 1.00 \\
\cline { 3 - 5 } & Yes & 0 & 660000 & 8.00 \\
\cline { 3 - 5 } & Yes & 1 & 385000 & 4.67 \\
\cline { 3 - 5 } & \multirow{4}{*}{0.06} & Yes & 5 & 297500 & 3.61 \\
\cline { 3 - 5 } & Yes & 10 & 222500 & 2.70 \\
\cline { 3 - 5 } & & 20 & 175000 & 2.12 \\
\hline
\end{tabular}

According to the results presented in Tab.1, it can be indicate that the benefit of cold expansion was weakened strongly by residual stress relaxation, the fatigue life enhancing ratio reduce one half within the first year as the residual circumferential stress at hole edge decreased from -160MPa to -96MPa at the same time.

Fatigue life enhancing ratio reduced to 2.05(2.12) after 20 years, which was equal to $25 \%$ of its initial value only. The results revealed that the influence of residual stress relaxation on fatigue life enhancing effect of cold expansionthe can be significant also.

\section{Conclusions}

(1) A 3-D finite element model was established to simulate the process of split sleeve cold expansion, stress relaxation and fatigue, fatigue lives under different situations are calculated.

(2) The FE simulation results show that the fatigue life enhancing ratio is inversely proportional to the stress relaxation time, the fatigue life enhancing ratio equivalent to $25 \%$ of its initial value after 20 years. The results reveal that the impact of residual stress relaxation on fatigue life enhancing effect of cold expansion is significant, which should be considered in application.

\section{References}

[1] YANG HongYuan, LIU WenTing: Journal of Mechanical Strength. Vol. 32 (2010), p. 446-450. (In Chinese)

[2] T.N. Chakherlou, J. Vogwell: Engineering Failure Analysis. Vol. 10 (2003), p. 13-24.

[3] M. Burlat, D. Julien, M. Levesque, T. Bui-Quoc, M. Bernard: Engineering Fracture Mechanics. Vol. 75 (2008), p. 2042 2061.

[4] H.D. Gopalakrishna, H.N. Narasimha Murthy, M. Krishna, M.S. Vinod, A.V. Suresh: Engineering Failure Analysis. Vol. 17 (2010), p. 361-368.

[5] Wyman Z, Zhuang, Gary R. Halford: International Journal of Fatigue. Vol. 23 (2001), p. 31-37.

[6] Kang KJ, Song JH, Earmme YY: Journal of Strain Analysis for Engineering Design. Vol. 42 (1989), p. 23-30.

[7] N.C. Mahendra Babu, T. Jagadish, K. Ramachandra, S.N. Sridhara: Engineering Failure Analysis. Vol. 15 (2008), p. 339-348.

[8] T.N. Chakherlou, A.B. Aghdam, A. Akbari, K. Saeedi: Materials and Design. Vol. 31 (2010), p. 2058-2066.

[9] GUAN Di, SUN Qin: Applied Mechanics and Materials. Vol. 117-119 (2012), p. 1656 1661.

[10] 《Handbook of China Aeronautical Materials》 Editorial Committee: Handbook of China aeronautical materials: Vol.3 Aluminum alloy, magnesium alloy. Beijing: Standards Press of China, 2002: 297-308.(In chinese)

[11] Yang F P. PhD Thesis, Xi’an: Northwestern Polytechnical University, 2010.

[12] Lemaitre J, Desmorat R. Engineering damage mechanics. Berlin: Springer, 2005: 26-75. 